\title{
Correlation of Thyroid Imaging Reporting and Data System [TI-RADS] and fine needle aspiration: experience in 1,000 nodules
}

\author{
Correlação entre a classificação Thyroid Imaging Reporting and Data System [TI-RADS] \\ e punção aspirativa por agulha fina: experiência com 1.000 nódulos
}

\begin{abstract}
Antonio Rahal Junior ${ }^{1}$, Priscila Mina Falsarella ${ }^{1}$, Rafael Dahmer Rocha ${ }^{1}$, João Paulo Bacellar Costa Lima ${ }^{1}$, Matheus Jorge Iani ${ }^{1}$, Fábio Augusto Cardillo Vieira ${ }^{1}$, Marcos Roberto Gomes de Queiroz ${ }^{1}$, Jairo Tabacow Hidal ${ }^{1}$, Miguel José Francisco Neto ${ }^{1}$, Rodrigo Gobbo Garcia ${ }^{1}$, Marcelo Buarque de Gusmão Funari ${ }^{1}$
\end{abstract}

\begin{abstract}
Objective: To correlate the Thyroid Imaging Reporting and Data System (TI-RADS) and the Bethesda system in reporting cytopathology in 1,000 thyroid nodules. Methods: A retrospective study conducted from November 2011 to February 2014 that evaluated 1,000 thyroid nodules of 906 patients who underwent ultrasound exam and fine needle aspiration. Results: A significant association was found between the TI-RADS outcome and Bethesda classification $(p<0.001)$. Most individuals with TI-RADS 2 or 3 had Bethesda 2 result $(95.5 \%$ and $92.5 \%$, respectively). Among those classified as TI-RADS $4 \mathrm{C}$ and 5 , most presented Bethesda $6(68.2 \%$ and $91.3 \%$, respectively; $p<0.001)$. The proportion of malignancies among TI-RADS 2 was $0.8 \%$, and TI-RADS 3 was $1.7 \%$. Among those classified as TI-RADS $4 \mathrm{~A}$, proportion of malignancies was $16.0 \%, 43.2 \%$ in $4 \mathrm{~B}, 72.7 \%$ in $4 \mathrm{C}$ and $91.3 \%$ among TI-RADS $5(p<0.001)$, showing clear association between TI-RADS and biopsy results. Conclusion: The TI-RADS is appropriate to assess thyroid nodules and avoid unnecessary fine needle aspiration, as well as to assist in making decision about when this procedure should be performed.
\end{abstract}

Keywords: Thyroid nodule/classification; Biopy, fine-needle; Thyroid gland/ultrasonography; Thyroid gland/citology

\section{RESUMO}

Objetivo: Apresentar a correlação entre o Thyroid Imaging Reporting and Data System (TI-RADS) e o sistema Bethesda, para relatar citopatologia em 1.000 nódulos tireoidianos. Métodos: Estudo retrospectivo realizado no período de novembro de 2011 a fevereiro de 2014, que avaliou 1.000 nódulos tireoidianos de 906 pacientes submetidos a exame de ultrassonografia e à punção aspirativa por agulha fina. Resultados: Observou-se associação significativa entre 0 TI-RADS e o resultado da classificação de Bethesda $(p<0,001)$. A maioria dos indivíduos com TI-RADS 2 ou 3 teve resultado citológico Bethesda 2 (95,5\% e 92,5\%, respectivamente). Entre aqueles classificados TI-RADS $4 C$ e 5, a maioria teve resultado Bethesda 6 (68,2\% e 91,3\%, respectivamente; $p<0,001)$. A proporção de malignidades em TI-RADS 2 foi $0,8 \%$ e em TI-RADS 3 foi $1,7 \%$. Entre TI-RADS $4 A$, foi de $16,0 \%$, 43,2\% em 4B, $72,7 \%$ em $4 C$ e em 5 foi de $91,3 \%(p<0,001)$, mostrando clara associação entre 0 TI-RADS e os resultados da biópsia. Conclusão: 0 TI-RADS é apropriado para avaliar nódulos da tireoide e evitar punção aspirativa por agulha fina desnecessária, além de auxiliar na decisão sobre quando este procedimento deve ser realizado.

Descritores: Nódulo da glândula tireoide/classificação; Biópsia por agulha fina; Glândula tireoide/ultrassonografia; Glândula tireoide/citologia

\section{INTRODUCTION}

Thyroid nodules are very prevalent - they are found in approximately $8 \%$ of adults by palpation, $41 \%$ by means of ultrasound (US), and in 50\% in autopsy pathological examination. ${ }^{(1)}$ Thyroid malignancy is relatively rare, and it is diagnosed in approximately $10 \%$ of all thyroid nodules. ${ }^{(2-4)}$ The appropriate indication of which nodules should undergo fine needle aspiration (FNA) and which

\footnotetext{
'Hospital Israelita Albert Einstein, São Paulo, SP, Brazil.

Corresponding author: Priscila Mina Falsarella - Avenida Albert Einstein, 627/701 - Morumbi - Zip code: 05652-900 - São Paulo, SP, Brazil - Phone: (55 11) 2151-0195 - E-mail: primina@gmail.com Received on: Feb 3, 2016 - Accepted on: May 8, 2016
} 
can be monitored is still under debate. In the past two decades several controversies regarding the malignant characteristics aroused, but there is no definitive classification yet. ${ }^{(1,5-7)}$

In the last 5 years, some publications have tried to establish a reliable guideline for thyroid nodule sonographic evaluation. ${ }^{(3-5,8,9)}$ Based on the already established Breast Imaging Reporting and Data System ${ }^{\circledast}$ (BI-RADS ${ }^{\circledR}$ ) for breast nodules, ${ }^{(10)}$ some reports suggested a categorization system of US features in thyroid nodules - the Thyroid Imaging Reporting and Data System (TI-RADS). The purpose of TI-RADS is to group the nodules into different categories with a similar percentage of malignancy as in BI-RADS ${ }^{\circledast}$. It is based on thyroid nodules classification, exclusively regarding B-mode ultrasonographic features, to reduce inter-observer and inter-device variability.

\section{OBJECTIVE}

To present the results of our initial experience in the correlation between TI-RADS and the Bethesda system for cytopathology reports of 1,000 thyroid nodules in patients who underwent sonographic evaluation, followed by fine needle aspiration, and classified according to TI-RADS system.

\section{METHODS}

The institutional review board approved this retrospective study, and the requirement to obtain Informed Consent form was waived. From November 2011 to February 2014, US scan of thyroid gland and neck area and US-guided FNA of thyroid focal nodules were performed by experienced physicians, in our intervention center. The Medical Ethics Committee of the organization approved the study under protocol number CAAE: 41699015.8.0000.0071.

A total of 1,000 thyroid nodules in 906 patients were analyzed and classified according to TIRADS, without prior knowledge of the cytological results. The US equipment used were the ATL HDI 5000 (Absolute Medical Equipment, Wesley Hills, New York, United States), IU 22 Philips (Philips Healthcare, Andover, Massachusetts, United States), Aplio 500 Platinum (Toshiba American Medical Systems, Tustin, California, United States) and My Lab 75 (Esaote, Genova, Italy), and the acquired images stored in the PACS System (Carestream Health, California, United States).

The TI-RADS classification ranged from 1 (negative findings) to 6 (known proved malignancy) and category 4 was further divided into subcategories 4A (low suspicion), 4B (intermediate suspicion) and 4C (moderate suspicion). The higher the grade of the nodule, the greater the risk of malignancy is (Table 1 and Figure 1).

Table 1. Thyroid Imaging Reporting and Data System (TI-RADS) classification

\begin{tabular}{lll}
\hline TI-RADS & Definition & Ultrasound features \\
\hline 1 & Negative & Normal thyroid \\
2 & Benign & Benign features \\
3 & Probably benign & Without suspicious features \\
$4 \mathrm{~A}$ & Low suspicion & One suspicion feature \\
$4 \mathrm{~B}$ & Intermediate suspicion & Two suspicion features \\
$4 \mathrm{C}$ & Moderate suspicion & Three or four suspicion features \\
5 & High suspicion & Five suspicion features \\
6 & Known proved malignancy & Confirmed malignancy \\
\hline
\end{tabular}
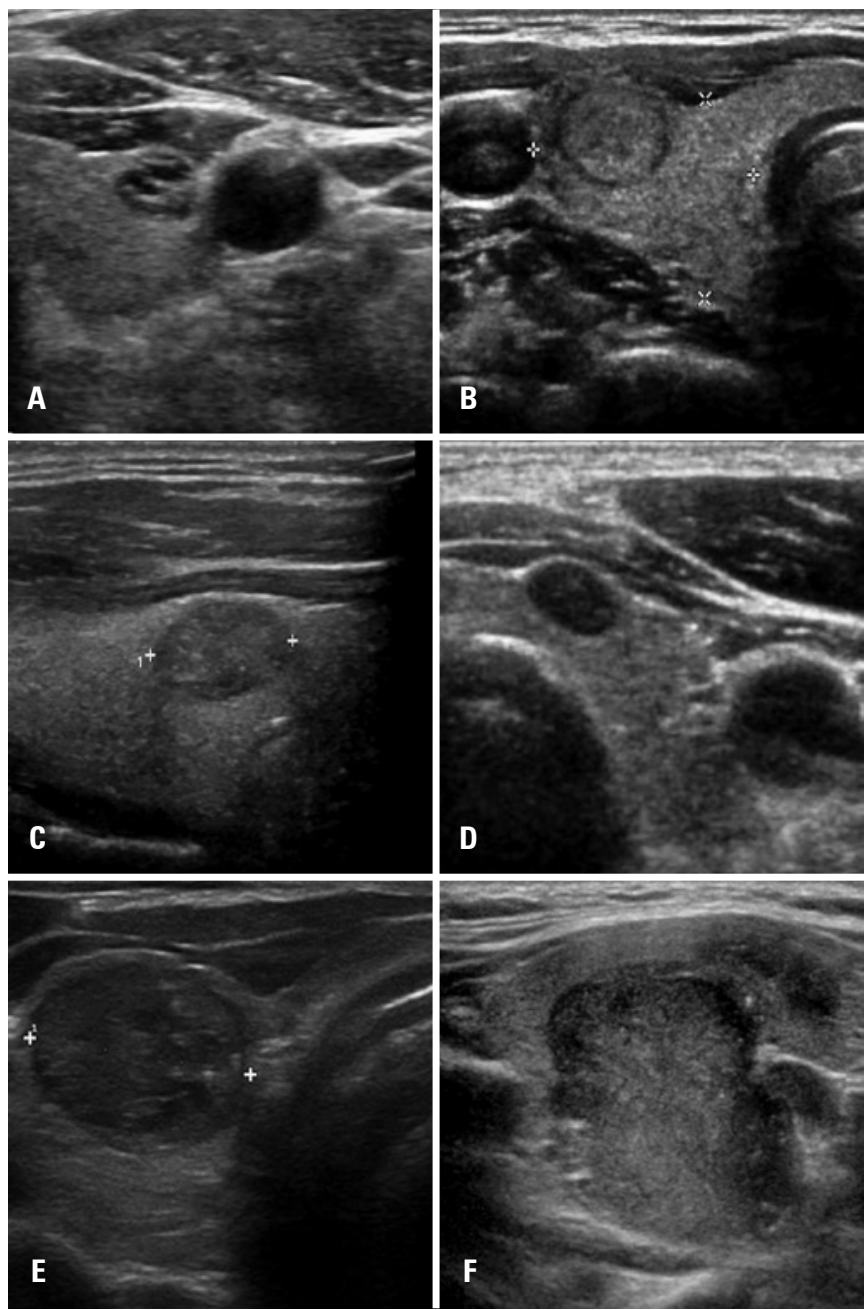

Figure 1. Examples of thyroid nodules submitted to cytological examination. $(\mathrm{A})$ Nodule classified as TI-RADS 2; (B) TI-RADS 3; (C) TI-RADS 4A; (D) TI-RADS 4B; (E) TI-RADS 4C; (F) TI-RADS 5; cases $A, B$ and $C$ were considered benign; cases $\mathrm{D}, \mathrm{E}$ and $\mathrm{F}$ were consider malignant according to Bethesda system ${ }^{(11)}$ 
The US features associated to higher malignancy risks were irregular margins, hipoechogenicity, marked hypoechogenicity (defined as solid nodules, without enhancement or spots, with areas of greater hypoechogenicity within the nodule, or in relation to other hypoechoic areas of the thyroid gland; in this situation, we considered both points), morphology longer than wide, and microcalcifications.

FNA was performed by freehand technique under US guidance, using a 23-gauge needle attached to a $20 \mathrm{cc}$ syringe. Upon aspiration, a negative pressure was maintained until blood appeared in the hub of the syringe. The anesthesia used was the combination of local anesthetic (lidocaine) and ice. Crossing thyroid vessels was avoided to prevent local bleeding; in mixed nodules, solid areas were chosen.

In all FNA procedures, prior to patient discharge, a cytologist assessed the sample to avoid unnecessary punctures and insufficient specimens. After this initial evaluation, experienced pathologists evaluated all samples according to Bethesda system (Table 2).

Table 2. The Bethesda System for Reporting Thyroid Cytopathology

\begin{tabular}{ll}
\hline Category & Meaning \\
\hline I & Non-diagnostic or inadequate \\
II & Benign \\
III & Atypia/follicular lesion of undetermined significance \\
IV & Follicular neoplasm or suspicious for follicular neoplasm \\
V & Suspicious for malignancy \\
VI & Malignant \\
\hline Source: Cibas et al. ${ }^{(11)}$ &
\end{tabular}

The relation between TI-RADS and Bethesda was evaluated through double entry tables, $\chi^{2}$ and Pearson's correlation tests. Considering the biopsy results as malignant or benign, to analyze the association we used binary logistic regression models and assessed the odds ratios of malignancy for each TI-RADS category. The odds ratios were expressed using $95 \%$ confidence interval $(95 \% \mathrm{CI})$. The tests were performed using the Statistical Package for Social Science (SPSS) for Windows, version 17.0, and considering the significance level $(\alpha)$ of $5 \%$.

\section{RESULTS}

One thousand examinations of 906 patients were carried out. Of the total of 1,000 examinations, 24 were Bethesda I and were excluded; hence, we had 976 complete examinations. The nodules classified as Bethesda cytology IV, V and VI were considered suspicious for malignancy.
Taking into account all nodules in the analysis, a significant association was observed between the TI-RADS and the Bethesda $(p<0.001)$ classification, and those with TI-RADS rating 2 or 3 were mostly Bethesda 2 (95.5\% and $92.5 \%$, respectively). Among those classified as TI-RADS 4C and 5 (68.2\% and $91.3 \%$, respectively), the majority was Bethesda 6 (Table 3 ).

Table 3. Thyroid Imaging Reporting and Data System (TI-RADS) and Bethesda correlation

\begin{tabular}{lcccccc}
\hline TI-RADS & \multicolumn{7}{c}{ Bethesda results } \\
\cline { 2 - 7 } classification & $\mathbf{2}$ & $\mathbf{3}$ & $\mathbf{4}$ & $\mathbf{5}$ & $\mathbf{6}$ & Total \\
\hline 2 & $\mathbf{n}(\%)$ & $\mathbf{n}(\%)$ & $\mathbf{n}(\%)$ & $\mathbf{n ( \% )}$ & $\mathbf{n}(\%)$ & $\mathbf{n}(\%)$ \\
\hline 3 & $120(96)$ & $4(3.2)$ & $0(0)$ & $0(0)$ & $1(0.8)$ & 125 \\
$4 A$ & $432(93.3)$ & $23(5)$ & $0(0)$ & $0(0)$ & $8(1.7)$ & 463 \\
$4 B$ & $192(73.3)$ & $28(10.7)$ & $6(2.3)$ & $1(0.4)$ & $35(13.4)$ & 262 \\
$4 C$ & $35(43.2)$ & $11(13.6)$ & $3(3.7)$ & $1(1.2)$ & $31(38.3)$ & 81 \\
5 & $3(13.6)$ & $3(13.6)$ & $1(4.5)$ & $0(0)$ & $15(68.2)$ & 22 \\
\hline Total & $1(4.3)$ & $1(4.3)$ & $0(0)$ & $0(0)$ & $21(91.3)$ & 23 \\
\hline & $783(80.2)$ & $70(7.2)$ & $10(1)$ & $2(0.2)$ & $111(11.4)$ & 976 \\
\hline
\end{tabular}

There was an unexpected malignancy case in a nodule that had been classified as TI-RADS 2. A retrospective revision of the images showed that the nodule, in fact, should have been classified as 3 (Figure 2A). Probably the nodule was misclassified by wrongly considering the solid part as spongiform and, in fact, it did not contain colloid foci. There was also one nodule classified as TI-RADS 5 that was benign. It was a case of thyroiditis, confirmed in follow-up US exams (Figure 2B). All the remaining percentages of malignancy in cytology were similar to BI-RADS ${ }^{\circledR}$ method, widely accepted and established.
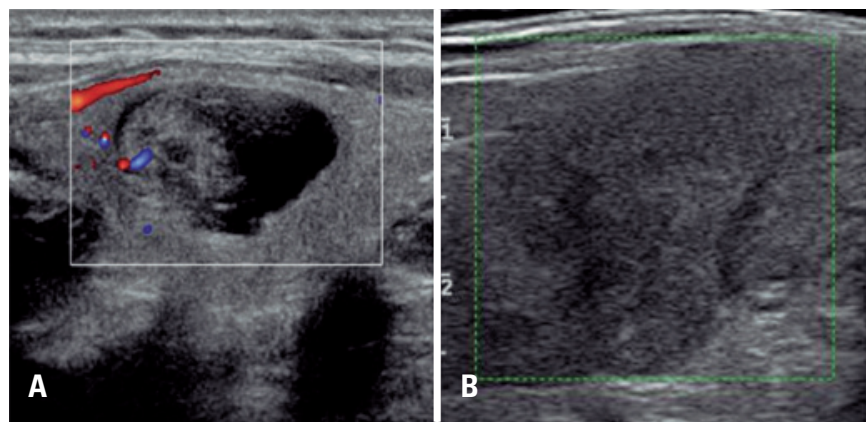

Figure 2. Thyroid ultrasound with unexpected results. (A) Nodule classified as TI-RADS 2 that showed malignancy in cytological examination. (B) Nodule classified as TI-RADS 5 with granulomatous thyroiditis in cytological examination (Bethesda II) 
In the analysis considering all nodules, the proportion of malignant nodules classified as TI-RADS 2 was $0.8 \%$, and among those TI-RADS 3 , it was $1.7 \%$. We classified as $4 \mathrm{~A} 16 \%, 43.2 \%$ as $4 \mathrm{~B}, 72.7 \%$ as $4 \mathrm{C}$ classification, and $91.3 \%$ as TI-RADS 5. The results of the logistic regression model was $\mathrm{p}<0.001$, showing a clear association between TI-RADS and biopsy results. The group rated TI-RADS 3 was considered as the reference for the model to be more numerous. The risk of malignancy for patients classified $4 \mathrm{~A}$ was estimated at 10.86-fold the risk for those rated as 3 (95\% CI: 5.023.5). For the individuals with $4 \mathrm{~B}$ classification, the risk of malignancy was estimated to be 43.27 -fold that for patients rated 3 (95\% CI: 18.95-98.92). The other estimated odds ratios are presented in table 4.

Table 4. Thyroid Imaging Reporting and Data System (TI-RADS) and correlation with risk of malignancy

\begin{tabular}{|c|c|c|c|c|c|}
\hline \multirow{2}{*}{$\begin{array}{l}\text { TI-RADS } \\
\text { All } \\
\text { nodules }\end{array}$} & \multicolumn{3}{|c|}{ Malignancy } & \multirow[b]{2}{*}{ OR 95\%CI } & \multirow[b]{2}{*}{$p$ value } \\
\hline & $\frac{\text { Benign }}{n(\%)}$ & $\frac{\text { Malignant }}{\mathrm{n}(\%)}$ & $\begin{array}{l}\text { Total } \\
\text { n (\%) }\end{array}$ & & \\
\hline 2 & $124(99.2)$ & $1(0.8)$ & 125 & $0.46(0.06-3,7)$ & 0.464 \\
\hline 3 & $455(98.3)$ & $8(1.7)$ & 463 & Reference & Reference \\
\hline $4 \mathrm{~A}$ & $220(84)$ & $42(16)$ & 262 & $10.86(5-23.52)$ & 0.002 \\
\hline $4 \mathrm{~B}$ & $46(56.8)$ & $35(43.2)$ & 81 & 43.27 (18.9-98.82) & $<0.001$ \\
\hline $4 C$ & $6(27.3)$ & $16(72.7)$ & 22 & $151.67(47-488.68)$ & $<0.001$ \\
\hline 5 & $2(8.7)$ & $21(91.3)$ & 23 & $597.19(119.3-2987.7)$ & $<0.001$ \\
\hline Total & $853(87.4)$ & $123(12.6)$ & 976 & & \\
\hline
\end{tabular}

95\%Cl: 95\% confidence interval; OR: odds ratio.

\section{DISCUSSION}

Thyroid US should be performed in the initial assessment of the gland. ${ }^{(12,13)}$ The FNA is an inexpensive and useful tool for detecting thyroid cancer, but it is an invasive procedure. In the management of thyroid nodule patients, recommending who should be submitted to FNA is still controversial. In the last decade, the improvement of Doppler US evaluation drew interest in rating thyroid nodules, based on spectrum and speed mapping parameters, which initially proved promising. In this context, the classification proposed by Chammas et al. ${ }^{(5)}$ emerged as one of the main methods used. However, the methodology has some limitations, including much variability inter-examiners and inter-devices, which is greater in evaluation by Doppler as compared to B-mode parameters. Similarly, the retrospective analysis of images is greatly compromised. Several classifications based on US features have been proposed in the last decade, in an attempt to facilitate this selection. However a consensus has not been established, given the difficulty of reproducibility of different classifications proposed, or even due to the low correlation between the US reports and cytology results. ${ }^{(3-5,8,9,12)}$

Currently there is a tendency to standardize the imaging evaluation of different organs ${ }^{(10,14,15)}$ with reliable and easily reproducible classifications. The main example is the already established BI-RADS ${ }^{\circledR}$ classification for breast nodules.

The TI-RADS classification aims to correlate US features to cytological classification, increasingly graduating the risk of a nodule being malignant, according to the number of features present in the US. Among diverse classifications, Horvath et al., ${ }^{(3)}$ by means of a prospective analysis, proposed ten US patterns to be analyzed during the examination and nodule classification from TI-RADS 2 to 6 (category 4 divided into $4 \mathrm{~A}$ and $4 \mathrm{~B}$ ) and estimated a malignancy risk of $14.1 \%$ in TI-RADS 3, 45\% in TI-RADS 4, and 89.6\% in TI-RADS 6. Kwak et al. ${ }^{(4)}$ proposed a TI-RADS classification through retrospective analysis of patients submitted to thyroid US and FNA, considering the risk of malignancy and subdivisions similar to the $\mathrm{BI}-\mathrm{RADS}^{\circledR}$ classification (that is, with three subdivisions for category 4), using five US criteria that can be added during thyroid evaluation. This article also described that a malignancy risk lower than $3 \%$ is expected for TI-RADS 3, a risk of 3.6 to $91.9 \%$ for TI-RADS 4, and of 88.7 to $97.9 \%$ for TI-RADS 5 .

The present study has differences in relation to that proposed by Horvath et al., ${ }^{(3)}$ such as being retrospective and with one more subdivision in the category 4 , by adding $4 \mathrm{C}$. Besides our purpose was to facilitate the classification process, reducing from ten to only four features in B-mode US considered in our classification. It also differed from the study by Kwak et al. ${ }^{(4)}$ in this issue, since these authors used five features in the classification, one more than ours. This difference relied on the nodule composition, that we judged as liable to mistakes in some cases, since many mixed nodules could generate uncertainty about their precise composition in ultrasonographic evaluation. Instead, we considered two points of marked hypoechogenicity, because the nodules with such characteristics have an increased risk of malignancy as compared to those slightly hypoechoic. ${ }^{(16,17)}$

Finally, our classification, unlike others proposed, does not use the sum of points for Doppler features. Although Doppler mapping help in thyroid US evaluation, ${ }^{(5,9,18)}$ its large-scale reproducibility is compromised due to the inter-examiner and inter-device variability. ${ }^{(19)}$

This study has some limitations, such as being retrospective, sonographic assessment performed by different operators and diverse US machines, use of 
cytology data instead of pathological data despite high sensitivity and specificity of cytology. Another limitation was the lack of uniformity of criteria for indicating puncture of nodules.

\section{CONCLUSION}

TI-RADS can be considered an appropriate classification in the assessment of thyroid nodules, in order to avoid unnecessary fine needle aspirations and to assist in making decision about when it should be performed. This classification improves communication and reduces confusion among physicians and patients. Our experience demonstrated that the TI-RADS classification is highly reproducible, since it is based on B-mode characteristics of the nodules, especially when performed by experienced radiologists, acquainted with its use.

\section{REFERENCES}

1. Frates $\mathrm{MC}$, Benson CB, Charboneau JW, Cibas ES, Clark OH, Coleman BG, Cronan JJ, Doubilet PM, Evans DB, Goellner JR, Hay ID, Hertzberg BS, Intenzo CM, Jeffrey RB, Langer JE, Larsen PR, Mandel SJ, Middleton WD, Reading CC, Sherman SI, Tessler FN; Society of Radiologists in Ultrasound. Management of thyroid nodules detected at US: Society of Radiologists in US consensus conference statement. Radiology. 2005;237(3):794-800.

2. Hoang JK, Lee WK, Lee M, Johnson D, Farrell S. US features of thyroid malignancy: pearls and pitfalls. Radiographics. 2007;27(3):847-60; discussion 861-5. Review.

3. Horvath E, Majis S, Rossi R, Franco C, Niedmann JP, Castro A, et al. An ultrasonogram reporting system for thyroid nodules stratifying cancer risk for clinical management. J Clin Endocrinol Metab. 2009;94(5):1748-51.

4. Kwak JY, Han KH, Yoon JH, Moon HJ, Son EJ, Park SH, et al. Thyroid imaging reporting and data system for US features of nodules: a step in establishing better stratification of cancer risk. Radiology. 2011;260(3):892-9.

5. Chammas MC, Gerhard R, de Oliveira IR, Widman A, de Barros N, Durazzo $M$, et al. Thyroid nodules: evaluation with power Doppler and duplex Doppler ultrasound. Otolaryngol Head Neck Surg. 2005;132(6):874-82.
6. Russ G, Royer B, Bigorgne C, Rouxel A, Bienvenu-Perrard M, Leenhardt L. Prospective evaluation of thyroid imaging reporting and data system on 4550 nodules with and without elastography. Eur J Endocrinol. 2013;168(5):649-55.

7. Park JY, Lee HJ, Jang HW, Kim HK, Yi JH, Lee W, et al. A proposal for a thyroid imaging reporting and data system for ultrasound features of thyroid carcinoma. Thyroid. 2009;19(11):1257-64.

8. Kwak JY. Indications for fine needle aspiration in thyroid nodules. Endocrinol Metab (Seoul). 2013;28(2):81-5. Review.

9. Lagalla R, Caruso G, Romano M, Midiri M, Novara V, Zappasodi F. [Echo-color Doppler in thyroid disease]. Radiol Med. 1993;85(5 Suppl 1):109-13. Italian.

10. American College of Radiology (ACR). ACR BI-RADS ${ }^{\circledR}$ : ultrasound. In: Brest imaging reporting and data system, brest imaging atlas. 4th ed. Reston (VA); American College of Radiology; 2003.

11. Cibas ES, Ali SZ. The Bethesda System for Reporting Cytopathology. Thyroid. 2009;19(11):1159-65.

12. Paschke R, Hegedüs L, Alexander E, Valcavi R, Papini E, Gharib H. Thyroid nodule guidelines: agreement, disagreement and need for future research. Nat Rev Endocrinol. 2011;7(6):354-61. Review.

13. Pacini F, Schlumberger M, Dralle H, Elisei R, Smit JW, Wiersinga W; European Thyroid Cancer Taskforce. European consensus for the management of patients with differentiated thyroid carcinoma of the follicular epithelium. Eur J Endocrinol. 2006;154(6):787-803. Erratum in: Eur J Endocrinol. 2006; 155(2):385.

14. American College of Radiology (ACR). Liver imaging reporting and data system [Internet]. Reston (VA): ACR; 2013 [cited 2016 Apr 18]. Available from: www.acr.org/Quality-Safety/Resources/LIRADS

15. Weinreb JC, Barentsz JO, Choyke PL, Cornud F, Haider MA, Macura KJ, et al. PI-RADS Prostate Imaging - Reporting and Data System: 2015, Version 2. Eur Urol. 2016;69(1):16-40.

16. Grani G, D'Alessandri M, Carbotta G, Nesca A, Del Sordo M, Alessandrini S, et al. Grey-Scale Analysis Improves the Ultrasonographic Evaluation of Thyroid Nodules. Medicine (Baltimore). 2015;94(27):e1129.

17. Seo H, Na DG, Kim JH, Kim KW, Yoon JW. Ultrassonoterapia risk stratification for malignancy in thyroid nodules: a four-tier categorization system. Eur Radiol. 2015;25(7):2153-62.

18. Papini E, Guglielmi R, Bianchini A, Crescenzi A, Taccogna S, Nardi F, et al. Risk of malignancy in nonpalpable thyroid nodules: predictive value of ultrasound and color-doppler features. J Clin Endocrinol Metab. 2002;87(5):1941-6.

19. Faria MA, Casulari LA. [Comparison of color Doppler-evaluated thyroid nodule classifications as described by Lagalla and Chammas]. Arq Bras Endocrinol Metabol. 2009;53(7):811-7. Portuguese. 